\title{
MENUMBUHKAN SIKAP KETERBUKAAN TERHADAP YANG LAIN: Perspektif Silang Budaya (Cross-Cultura)
}

\author{
Andi Eka Putra \\ Universitas Islam Negeri Raden Intan Lampung \\ andiekaputra@radenintan.ac.id
}

\section{Abstract}

$V$ arious perspectives in fostering an attitude of openness to others (the others). One of them is a cross-cultural or cross-cultural perspective. Cross culture or cultural crossing is a way that combines two or more elements of culture which are then crossed, transplanted, mated or brought together, so that new cultures appear fresh, creative and dynamic. Cross-cultural studies were introduced by Edward Burnett Tylor and Lewis H. Morgan in the science of anthropology which later developed into the realm of culture. The cross-cultural perspective can now be applied freely to anything that refers to anything about comparisons of cultural differences, including religious comparisons. The ultimate goal is to minimize conflict and build sincere co-existence or openness with others.

\section{Abstrak}

Beragam perspektif dalam menumbubkan sikap keterbukaan terbadap yang lain (the others). Satu di antaranya adalah perspektif silang budaya atau crosscultural. Silang budaya atau persilangan kebudayaan adalah suatu cara yang memadukan dua unsur atau lebih kebudayaan yang kemudian disilangkan, dicangkokkan, dikawinkan atau dipertemukan, sehingga muncul kebudayaan baru yang segar, kreatif dan dinamis. Studi cross-cultural dikenalkan oleh Edward Burnett Tylor dan Lewis H. Morgan dalam ilmu antropologi yang kemudian berkembang ke ranab kebudayaan. Perspektif cross-cultural kini dapat 
diterapkan secara bebas kepada sesuatu yang merujuk kepada apa pun mengenai perbandingan tentang perbedaan-perbedaan kebudayaan, termasuk, perbandingan agama. Tujuan utamanya adalah meminimalisir konflik dan membangun koeksistensi atau sikap keterbukaan yang tulus dengan yang lain.

Keywords: Cross-Culture, Cross-Cultural, Religious Openness

\section{A. Pendahuluan}

Dalam perspektif sosiologis, manusia tak mungkin hidup sendirian, terisolir satu dengan yang lainnya, atau hidup hanya dalam satu suku atau satu golongan. Sebab, manusia tidak dapat hidup sendiri terus-menerus; ia membutuhkan teman, relasi, juga komunikasi. Hakekat manusia pada dasarnya berkelompok, baik kelompok yang kecil seperti suku-suku yang terpencil maupun kelompok yang besar seperti pada negara-negara yang modern, hal ini sesuai dengan kondisi kemanusiaan. Manusia menurut fitrahnya adalah makhluk sosial Artinya, manusia dapat hidup sempurna apabila ia hidup berkelompok dan bermasyarakat. Dengan kata lain manusia adalah makhluk sosial karena memang demikian ia diciptakan.

Dari keragaman etnik dan budaya itu dibutuhkan suatu pendekatan komunikasi antarbudaya. Di sini komunikasi merupakan proses sosial dimana individu-individu menggunakan simbol-simbol untuk menciptakan dan menginterpretasikan makna dalam lingkungan mereka. Ketika komunikasi dipandang secara sosial, komunikasi selalu melibatkan dua orang yang berinteraksi dengan berbagai niat, motivasi dan kemampuan membangun identitas budaya bersama.

Tak berlebihan bila para pakar komunikasi kerapkali mengatakan bahwa komunikasi adalah ciri instrinsik yang ada pada manusia yang sekaligus membedakan manusia dari makhluk lain. Proses komunikasi inilah yang selama ini menjadi sarana dan alat manusia menyampaikan pesan, mengelola persoalan dan berbagai problema sosial, membangun ikatan kebersamaan dan sekaligus 
sebagai pemecah beragam masalah yang disebabkan oleh kesenjangan komunikasi. ${ }^{1}$

Komunikasi sosial merupakan sarana membangun kohesi atau ikatan kebersamaan dalam suatu komunitas. Melalui komunikasi sosial, berbagai kesenjangan dapat dinegosiasikan, didiskusikan dan dicarikan pemecahan masalahnya secara beradab. Proses komunikasi sosial menuntut adanya saling pengertian dua belah pihak sehingga proses komunikasi berjalan dengan lancar dan baik.

Dalam kehidupan sosial-budaya yang multikompleks, komunikasi menjadi keharusan, kalau bukan keniscayaan. Komunikasi lintas budaya dan lintas suku dapat dibangun melalui beragam cara. Di antaranya melalui teori silang-budaya (cross-cultural).

Artikel ini akan dimulai dengan sebuah tesis sederhana bahwa kebudayaan memiliki kedudukan yang menentukan atas terjadinya perubahan sosial politik suatu bangsa. ${ }^{2}$ Pendukung teori ini perlu untuk mengenal, mengidentifikasi dan melakukan perbandingan atas keragaman budaya yang lain secara luas, mulai dari budaya yang menghambat kemajuan maupun yang mendorong kemajuan. Hal ini berarti memasuki wilayah kajian silang-budaya (cross-cultural) yang telah dilakukan oleh para ahli di bidang antropologi dan sosiologi.

Studi mengenai cross-cultural’ merupakan sebuah spesialisasi dalam antropologi yang menggunakan data lapangan dari beragam masyarakat untuk menguji ruang lingkup perilaku manusia dan menguji hipotesis tentang perilaku manusia dan budaya. Studi crosscultural diterapkan secara luas dalam ilmu-ilmu sosial, khususnya dalam antropologi budaya dan psikologi. Studi ini mulai dilakukan oleh para antropolog abad ke 19 seperti Edward Burnett Tylor dan Lewis H. Morgan. ${ }^{4}$ 2001), h. 4

${ }^{1}$ Jalaluddin Rakhmat, Ilmu Komunikasi, (Bandung: Rosda Karya, Bandung,

2 Alo Liweri, Makna Budaya dalam Komunikasi Antarbudaya, (Yogyakarta: Pelangi Aksara), 2015.

${ }^{3}$ Studi cross-cultural dikenalkan pertama kali kira-kira tahun 1930-an dalam studi antrpologi budaya

${ }_{4}^{4}$ Ibid., h. 19 


\section{B. Gagasan Silang-Budaya}

Istilah cross-cultural sendiri, silang budaya, muncul dalam ilmu sosial pada tahun 1930, sebagai pengaruh dari Survey cross-cultural yang dilakukan oleh George Peter Murdock. Dalam karyanya Social Structure ia menyajikan sebuah sintesis dari lima produk ilmu sosial yang berbeda—satu tehnik riset dan empat sistem teori. ${ }^{5}$

Menurut Carol R. Ember dalam Cross-Cultural Research Methods, istilah cross-cultural dapat diterapkan secara bebas kepada sesuatu yang merujuk kepada apa pun mengenai perbandingan tentang perbedaan-perbedaan kebudayaan. Ia juga menjelaskan bahwa riset cross-cultural tertarik kepada sebab dan akibat dari keragaman budaya yang melintasi sebuah domain yang luas, secara umum di seluruh dunia. ${ }^{6}$

\section{Silang Budaya: Melampaui Konflik Menuju Koeksistensi}

Tidak mengherankan jika Huntington dalam The Clash of Civilization menilai bahwa identitas budaya dan agama merupakan sumber utama bagi konflik pasca Perang Dingin.Meskipun tidak sedikit yang keberatan dengan pendapat Huntington tersebut, namun setidaknya budaya sebagai potensi konflik di masa mendatang memang perlu diwaspadai.

Secara umum budaya memang terkait dalam semua konflik sebab konflik muncul dalam hubungan diantara sesama manusia. Cara kita menamai, membingkai, menyalahkan, dan upaya untuk menjinakkan konflik, secara mendalam dipengaruhi oleh budaya. Karena itu, budaya lebih daripada sebuah topik yang terkait dengan konflik dan resolusi konflik-ia merupakan sebuah bagian integral dari semua interaksi, baik harmonis maupun konfliktual.

Budaya memainkan peran sentral dalam sebuah konflik. Sebagai contoh, konflik Israel-Palestina atau India-Pakista atas

${ }^{5}$ Kiki Muhamad Hakiki dan Zaenal Muttaqien, Konflik dan Integrasi Sosial (Telaah Buku A. Malik MTT berjudul 'Pura dan Masjid; Konflik dan Integrasi Pada Suku Tengger Jawa Timur), Al-AdYaN/Vol.IX, N0.2/Juli-Desember/2014, h. 44.

6 Alo Liweri, Teori-Teori Komunikasi Antarbudaya, (Yogyakarta: Pelangi Aksara, 2015), h. 63 
Kashmir tidak hanya sekedar masalah territorial, batas wilayah, dan kedaulatan. Hal itu juga tentang pengakuan, representasi dan legitimasi atas identitas dan jalan hidup yang berbeda.

Keragaman budaya memang dapat menjadi potensi konflik. David Levinson menulis sebuah ensiklopedia Aggression and Conflict: $A$ Crosss-cultural Encyclopedia, yang menunjukkan bagaimana orang melukai satu sama lain dan bagaimana orang belajar untuk hidup damai bersama. Dalam keragaman budaya terkandung unsur perbedaan etnis, agama, bahasa, tradisi nilai dan kepercayaan yang rentan terhadap konflik, baik karena ketakukan, kecurigaan dan kesalah pahaman yang kemudian melahirkan sikap diskriminatif bahkan kekerasan dan kriminalitas - seperti pembersihan etnis (ethnic cleansing) dan peperang,baik perang fisik maupun perang budaya. Perang budaya (culture wars), ini seperti yang terjadi di Eropa yang ketika memasuki abad ke 19, muncul Negara-bangsa konstitusional dan demokratis yang diiringi oleh konflik intensif antara Katolik dan kekuatan antiklerik. Puncaknya, konflik ini menyentuh hampir semua ruang kehidupan sosial: sekolah, kontrol ruang publik, memori rakyat, hingga simbol kebangsaan.

Jonathan H. Turner mendefinisikan konflik budaya sebagai konflik yang disebabkan oleh perbedaan-perbedaan nilai budaya dan kepercayaan yang menempatkan orang pada perasaan asing satu sama lainnya. Konflik budaya termasuk konflik yang sulit dipecahkan karena setiap kebudayaan memiliki pandangan dan nilai yang berbeda terhadap suatu masalah, seperti perbedaan pandangan terhadap aborsi, perbudakan, gender, dll yang menimbulkan konflik. Dan masih banyak lagi sederetan konflik budaya seperti yang terjadi di Cina, Jepang, Vietnam, Uni Soviet, Amerika Latin, Afrika, dst. yang mana di masa mendatang, spektrum konflik akan melampaui perang dalam bentuk dan level yang dalam yang membuat cara-cara konvensional tidak efektif untuk memecahkannya.

Namun keragaman budaya tidak mesti mengarah kepada konflik, bahkan sebaliknya bisa terjadi koeksistensi. Hal ini seperti yang terjadi di wilayah semenanjung Iberia abad pertengahan dimana tiga agama dan kebudayaan yang berbeda, yaitu Islam, Kristen dan Yahudi dapat hidup berdampingan. Mereka dapat saling berkoeksistensi dan melakukan hubungan politik, ekonomi dan kebudayaan. Ini telah dimulai sejak kaum Muslim mengusai Spanyol 
mulai abad ke 8 M. Meskipun masa-masa indah harmonis ini harus berakhir, namun setidaknya hal ini dapat menjadi bukti bahwa koeksistensi bisa terjadi dalam keragaman budaya.

\section{Silang Budaya di Era Globalisasi: Belajar dari Keunggulan Budaya Cina dan Taiwan}

Dalam suatu dunia yang saling terhubung dan tersatukan oleh kemajuan teknologi informasi dan komunikasi, atau disebut era globaliasi, maka semua bentuk keragaman budaya akan saling bertemu dan berinteraksi satu sama lain. Hal ini akan menciptakan konsekuensi yang berbeda. Peter L. Berger, seperti dikutip HsinHuang Michael Hsiao, memformulasikan sebuah tipologi dengan empat kemungkinan konsekuensi dari interseksi dari kekuatan globalisasi dan budaya indigenus, ${ }^{7}$ yaitu:

1. Penggantian kebudayaan lokal oleh kebudayaan yang terglobalisasi

2. Koeksistensi kebudayaan global dan lokal tanpa ada persatuan yang signifikansi dari keduanya

3. Sintesis dari kebudayaan global universal dengan kebudayaan indigenus partikular

4. Penolakan kebudayaan global oleh reaksi lokal yang kuat

Kita dapat melihat contoh yang berbeda dari masing-masing ke empat tipologi di atas. Di sini penulis ingin membatasi kepada kasus Cina dan Taiwan sebagai contoh. Kebangkitan-kembali Cina sebagai sebuah pengendali ekonomi dan politik global menjadi salah satu momen yang menentukan dalam sejarah dunia. Sementara itu terdapat pertumbuhan literatur yang mencoba menganalisis konsekuensi kebangkitan Cina bagi perkembangan di tempat lain, mayoritas darinya menguji dampak perdagangan, investasi, geopolitik Cina, dan lainnya atas Negara tertentu atau dunia.

Berlangsungnya perkembangan ekonomi yang sangat cepat di Cina Daratan betul-betul merupakan sebuah keajaiban ekonomi dan juga merupakan sebuah mesin yang sangat kuat bagi pertumbuhan kemajuan ekonomi global. Dari semua industri utama di Cina Daratan, industri elektronik adalah yang berkembang paling

${ }^{7}$ Peter L. Berger, Agama sebagai Konstruksi Sosial, terj. A. Sudiarmadji, (Jakarta: LP3ES, 1996), h. 88 
cepat, dan telah menjadi pilar bagi ekonomi Cina Daratan. Menurut statistik dari Informasi Kementrian, pada tahun 2002, industri informasi elektronik Cina Daratan mencapai nilai output 1536.167 milyar RMB, dengan nilai tambah 226.357 milyar RMB dan income penjualan 1120.347 milyar RMB, menempatkan Cina Daratan disamping Amerika dan Jepang sebagai produsen utama ketiga dari produk IT di seluruh dunia.

Dilihat dari ekspornya, sekarang Cina merupakan produsen elektronik dan ICT terbesar di dunia, dan dalam hal produk dengan skill tinggi dan teknologi-intensif, prestasi Cina mulai setara dengan Korea Selatan.

Di sisi lain kemajuan sains dan teknologi Cina semakin menunjukkan kekuatannya. Menurut Prof. Dr. Ing. Yongxiang Lu, President of the Chinese Academy of Science, modernisasi telah dipandang sebagai sebuah revolusi transformatif dalam sejarah modernisasi umat manusia. Demikianlah, Chinese Academy of Sciences (CAS) memutuskan untuk memberikan prioritas tertinggi kepada jalan riset sains dan teknologi bagi area priorotas dalam proses modernisasi Cina.

Sementara itu dari Taiwan kita dapat belajar bagaimana budaya global dan budaya lokal bisa saling berkoeksistensi dan mendorong kemajuan, seperti halnya dalam budaya ekonomi. Para kapitalis Taiwan, dengan perdagangan internasional dan investasi asingnya yang signifikan sejak tahun 1960, telah mengintegrasikan ekonomi Taiwan ke dalam pasar dunia. Diantara sektor yang berbeda dari perusahaan bisnis Taiwan, sebuah persentase yang tinggi dalam satu cara atau lainnya dihubungkan dengan masyarakat bisnis global. Lebih dari tiga dekade terakhir, hubungan mereka dengan bisnis internasional dan para CEO, manajer dan teknisi berjalan intens. Belajar dan bertukar diantara masing-masing pola kultur-bisnis antara pengusaha Taiwan dengan perusahaan dan investor asing berjalan secara konstan, walaupun dalam banyak kasus penguasaha Taiwanlah yang belajar dari rekan Amerika dan Jepang, khususnya dalam dekade sebelum tahun 1990. Di saat yang sama banyak dari para pengusaha internasional yang telah mendirikan jaringan korporat di Taiwan belajar mengadaptasikan praktek bisnis mereka sesuai dengan kondisi lokal. 
Adalah juga menarik untuk dicatat bahwa banyak dari manajer lokal di Taiwan yang bekerja di firma internasional telah mengembangkan pola perilaku ganda. Di tempat kerja, umumnya mereka berperilaku persis seperti kelas manajer yang terglobalisasi lainnya; di masyarakat lokal dimana firma asing berada, mereka tidak hanya mengubah gaya Inggris menjadi Minnan dan Hakka lokal, mereka juga mengubah mind-set mereka. Bagi kebanyakan mereka, melakukan bisnis atau menjalankan perusahaan adalah satu hal, namun terdapat aspek kehidupan lainnya, dan bisnis bukanlah segalanya. Untuk bertindak seperti seorang pengusaha atau manajer internasional adalah sebuah perilaku yang dipelajari bagi tempat kerja-sebuah kode perilaku yang diadopsi yang merupakan sebuah "penambahan" bukannya "penggantian" atas apa yang telah dipelajari mengenai hidup dari kebudayaan lokal.

\section{Silang Budaya: Mengambil yang Terbaik untuk Kemajuan}

Sebagai sebuah sistem pemikiran dan nilai, serta perilaku kolektif (collective behavior) kebudayaan memiliki kedudukan sentral dalam menentukan kehidupan sosial, politik dan ekonomi-dan demikian juga sebaliknya. Hubungan yang saling mempengaruhi ini merupakan sebuah fenomena yang sangat kompleks dan tidak bisa disederhanakan. Terlebih lagi dengan adanya keragaman budaya yang berbeda dari setiap bangsa di belahan dunia ini, sehingga masingmasing memiliki kasus yang unik, berbeda dan khas.

Dalam hal ini-sesuai dengan uraian di atas-ada beberapa unsur penting yang perlu di garis bawahi, yaitu: Pertama, jika budaya memiliki peranan yang menentukan maka sangat penting bagi suatu bangsa untuk merevitalisasi peran budaya untuk mendorong kemajuan. Sebab dalam kenyataannya tidak semua budaya cocok untuk mendorong kemajuan, sebagian malah menjadi penghambat kemajuan, seperti yang ditunjukkan oleh Gunnar Myrdal yang menilai faktor kemiskinan Negara-negara Asia diantaranya adalah karena latar belakang budaya mereka—seperti sikap irasional massa rakyat.

Kedua, keragaman budaya tidak semestinya mempertajam konflik dan pertentangan, tetapi perlu diarahkan kepada suasana dialog, kerjasama dan koeksistensi. Keragaman budaya justru merupakan peluang untuk terus belajar, bukan sebagai medan 
konflik. Meskipun potensi konflik tidak bisa dihilangkan sama sekali, namun setidaknya bisa diperkecil. Jangan sampai menjadi konflik berskala global seperti yang diprediksi oleh Huntington dalam The Clash of Civilizations atau benturan peradaban.

Ketiga, persilangan budaya merupakan sebuah peluang untuk saling belajar dan menyerap keungulan-keunggulan dari berbagai budaya yang berbeda. Jika kita belajar dari sejarah maka akan nampak bahwa hampir semua peradaban besar yang pernah muncul ke panggung dunia tidak pernah lepas dari "pinjam-meminjam" dengan berbagai peradaban lainnya yang hidup sezaman.

Dari keempat teori budaya di atas, semuanya dapat dijadikan sebagai acuan dalam proses komunikasi antar etnik. Relasi sosial antar etnik di Indonesia, disadari atau tidak, seringkali diwarnai konflik, baik yang berbasiskan ekonomi maupun politik serta etnik atau budaya. Konflik etnik bukan saja menyangkut warga Tionghoa yang seringkali dianggap sebagai orang luar, sekali pun lahir dan hidup di Indonesia sepanjang masa, tapi juga antarwarga pribumi, antarssama Muslim, seperti yang pernah terjadi antara warga pendatang Madura dengan warga Dayak di Sampit, Kalimantan Tengah, atau antara Lampung dan Bali di Kalianda Lampung, dan sebagainya.

Eddie Lembong menawarkan teori penyerbukan silang antarbudaya untuk mengatasi kesenjangan komunikasi antaretnik yang sebetulnya sama dengan silang budaya atau cross-cultural. ${ }^{8}$ Eddie Lembong meyakini bahwa satu dari jalan terbaik yang dapat membantu hubungan harmonis antaretnik adalah "Cross Cultural Fertilization", yaitu penyerbukan silang antarbudaya dalam membangun sebuah bangsa plural atau majemuk yang kuat dengan fondasi keberagaman etnik yang terdapat di Indonesia. Eddie Lembong termasuk pendukung kuat yang melihat bahwa karakter dan budaya bangsa adalah factor terpenting dalam membangun sebuah nasion.

Adapun yang dimaksud dengan strategi penyerbukan silang antarbudaya oleh Eddie Lembong tidaklain adalah usaha membangun keterbukaan dan pengakuan akan "yang lain" (the others). Strategi inti penyerbukan silang antarbudaya adalah gagasan membangun

8 Aan Rukmana dan Eddie Lembong (ed), Penyerbukan Silang Antarbudaya: Membangun Manusia Indonesia, (Jakarta: PT. Elex Media Kompatindo, 2015), h. 1-20 
Indonesia yang multi-etnik dalam sebuah kebersamaan yang saling menyapa. "Inilah puncak evolusi pemikiran saya sejak muda", tulis Eddie Lembong dalam buku yang telah disebutkan di muka.

Dengan jalan silang antarbudaya, etos kerja positif yang dimiliki satu kelompok etnik lain bisa diambil dan diterapkan oleh etnik yang lain pula sehingga melahirkan sebuah budaya baru, etos baru, semangat baru dan pemecahan masalah baru. Apalagi Indonesia dikenal sebagai bangsa yang majemuk dengan tingkat keberagaman yang tinggi, teori ini sangat relevan. ${ }^{\text {? }}$

Jika kita menengok fakta lapangan, keberagaman budaya yang dimiliki Indonesia bisa menjadi modal atau aset untuk mengubah kehidupan rakyat Indonesia menjadi lebih baik atau menjadi modal sosial dalam pergaulan. Etos kerja warga Tionghoa Indonesia yang ulet dan gigih, misalnya, bisa diadopsi oleh budaya lain yang tidak memiliki kebiasaan itu. ${ }^{10}$

Pertanyaan selanjutnya adalah: apakah gagasan pokok di balik persilangan budaya ini? Kesadaran bahwa budaya Indonesia masih terus perlu diperkuat dalam konteks globalisasi. Persilangan budaya berarti usaha mempertemukan atau memadukan semua unsur yang baik untuk menghasilkan budaya Indonesia yang makin baik. Selain upaya-upaya state building, sangatlah perlu cultural building, perbaikan budaya dan etika manusia dalam rangka nation building dan membangun peradaban plural yang harmonis dan bumanis.

Istilah persilangan budaya memang lebih dekat dengan tumbuh-tumbuhan. Sebagian studi kebudayaan saat ini banyak menyerap metafor tanaman, sperti hibrida, perkawinan silang, pencangkokakan, dan sebagainya. Selain terkesan alamiah, karena berasal dari tanaman atau tumbuhan, persilangan atau penyerbukan dilakukan secara terukur, penuh perhitungan dan rancangan yang matang.

Ide persilangan atau penyerbukan budaya sangat berbeda dengan ide asimilasi budaya atau multikulturalisme. Ide asimilasi budaya yang secara politik digulirkan oleh Partai Tionghoa Indonesia (PTI) sejak tahun 1932 yang kemudian mendapat sambutan positif

${ }^{9}$ Ibid., h. 9

10 Aan Rukmana dan Eddie Lembong (ed), Penyerbukan, h. 18 
dari pemerintahan sejak tahun 1960 dan dipraktekkan dengan massif pada era Orde Baru berangkat dari pandangan bahwa budaya minor dalam hal ini budaya Tionghoa harus masuk ke dalam budaya mayor.

Maka sejak saat itu, banyak warga keturunan Tionghoa yang berubah nama menjadi nama yang Jawa dan lain sebagainya sebagai bagian dari implementasi gagasan asimilasi. Ide ini tidaklah buruk, akan tetapi untuk konteks saat ini perlu ditinjau kembali sesuai dengan konteks kekinian.

Dalam konsep asimilasi budaya yang mendahului crosscultural, masih ada anggapan budaya mayoritas dan budaya minoritas, jadi sebuah budaya dilihat bukan dari sisi kualitasnya melainkan dari kuantitasnya. Ini berbeda dengan ide penyerbukan silang antarbudaya yang berangkat dari kualitas masing-masing budaya, sehingga tidak perlu dipersoalkan apakah budaya itu minoritas asalkan ia memiliki keunggulan maka dapat kita pelajari juga.

Ide persilangan kebudayaan juga berbeda dengan ide multikulturalisme. Praktek multikulturalisme yang diterapkan di Kanada dan Australia juga di sebagian negara-negara Eropa tidaklah cocok bila diterapkan di Indonesia. Ide multikulturalisme yang berangkat dari pandangan bahwa masing-masing budaya diberikan kebebasan untuk tumbuh berkembang sesuai dengan keunikannya masing-masing. Ibarat taman yang ditanami banyak pohon, demikian itulah multikulturalisme. Masing-masing budaya yang ada tumbuh sesuai dengan kediriannya. Tidak ada dialog yang mendalam apalagi usaha saling melebur dalam gagasan tersebut.

\section{Penutup}

Dari paparan singkat di atas, dapat diambil pemahaman bahwa silang budaya bertujuan membangun sikap keterbukaan dengan yang lain. Sikap ini yang saat ini dibutuhkan Indonesia dengan berbagai etnik yang unik dan beragam, dan dapat diperkawinkan silang, karena perkawinan silang ini akan melahirkan buah atau anak yang jika dua kebudayaan unggul dikawinkan akan menghasilkan anak yang kuat dan berkarakter baik. 
Andi Eka Putra

Dalam konteks etnik, maka masing-masing etnik dapat diserbuk-silangkan sehingga menjadi budaya unggul yang dapat terus tumbuh mengharumkan tanah Indonesia. Untuk memulainya, kita perlu memaksimalkan pendidikan yang menghargai pembentukan karakter yang dimulai dari level anak-anak sampai kalangan orang tua, termasuk para guru yang terlibat dalam proses pendidikan dan pengajaran. 


\section{Daftar Pustaka}

Abdullah dan Wulat Wigati, Sosiologi. Jakarta: Grasindo, 2006.

Aw, Suranto, Komunikasi Sosial Budaya. Yogyakarta: Graha Ilmu, 2010.

DeVito, Joseph, Komunikasi Antar Manusia, Jakarta: Professional Books, 1997.

Golemen, Daniel, Social Intelligence. Terj. Hariono S. Imam, Jakarta: Gramedia, 2015.

Hakiki, Kiki Muhamad, dan Zaenal Muttaqien, Konflik dan Integrasi Sosial (Telaah Buku A. Malik MTT berjudul "Pura dan Masjid; Konflik dan Integrasi Pada Suku Tengger Jawa Timur), AlAdYaN/Vol.IX, N0.2/Juli-Desember/2014.

Hariwijaya, Muhammad, Tata Cara Penyelenggaraan Perkawinan Adat Jawa, Yogyakarta: Hanggar Kreator, 2008.

Haryono, Anton, Perkawinan Silang dan Perkawinan Campuran, Yogyakarta: Lapardz, 2001.

Koentjaraningrat, Kebudayaan, Mentalitas dan Pembangunan, Jakarta: Gramedia, 1992.

L. Berger, Peter, Agama sebagai Konstruksi Sosial, terj. A. Sudiarmadji, LP3ES, Jakarta, 1996

Liweri, Alo, Makna Budaya dalam Komunikasi Antarbudaya. Yogyakarta: Pelangi Aksara, 2002.

, Teori-Teori Komunikasi Antarbudaya, Yogyakarta: Pelangi Aksara, 2015.

, 2005. Gatra Gatra Komunikasi Antarbudaya,:Yogyakarta: Pustaka Pelajar

Lombard, Denys, Nusa Jawa: Silang Budaya, Jilid I, terj. S. Hartono, Jakarta: Gramedia Pustaka Utama, 1996.

May, Larry. (Ed). Etika Terapan: Sebuah Pendekatan Multikultural bagi Masalah Etnik, terj. Imran Rosyidi dan Zehra Nihayati, Yogyakarta: Tiara Wacana, 2001. 
Muhadjir, Noeng, Metode Penelitian Kualitatif, Yogyakarta: Rake Sarasin, 1989.

Peursen, Van, Strategi Kebudayaan, Yogyakarta: Kanisius, 1996

Rakhmat, Jalaluddin, Ilmu Komunikasi, Bandung: Rosda Karya, 2001.

Rukmana, Aan, dan Eddie Lembong (ed)., Penyerbukan Silang Antarbudaya: Membangun Manusia Indonesia, Jakarta: PT. Elex Media Kompatindo, 2015.

Triyana, Bonnie, Eddie Lembong Mencintai Tanah Air Sepenub Hati. Jakarta: Penerbit Buku Kompas, 2011.

West, Richard, dan Lynn H. Turner. 2009. Pengantar Teori Komunikasi: Analisis dan Aplikasi. Jakarta: Salemba Humanika 